\title{
Gala: protagonizando a dança das nossas vidas
}

Gala: starring the dance of our lives

Marcia Abujamra

Marcia Abujamra

Diretora de teatro, roteirista e produtora.

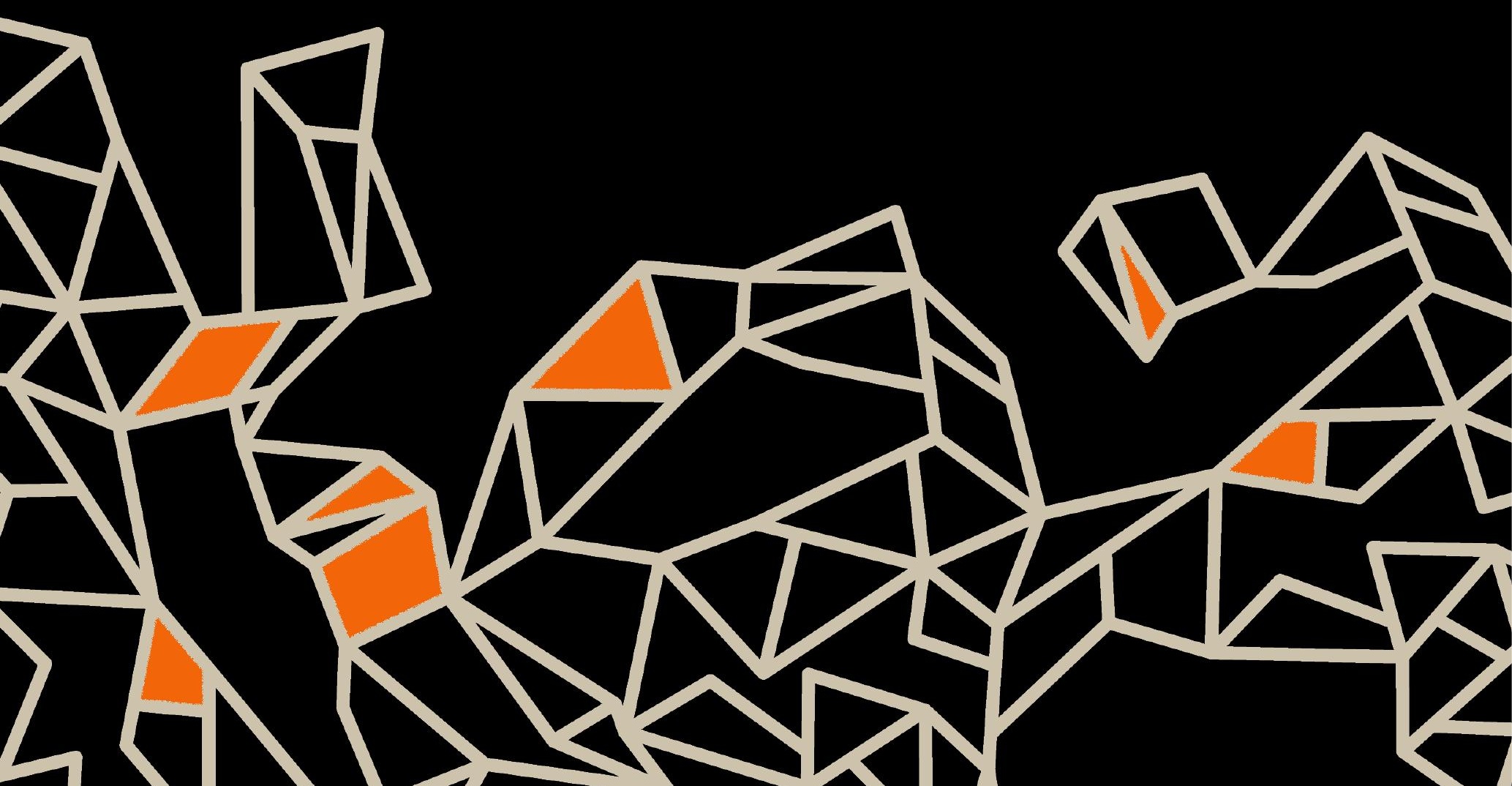




\section{Resumo}

Este artigo é uma reflexão sobre o espetáculo Gala, do coreógrafo francês Jérôme Bel, apresentado em São Paulo como parte da mostra FranceDanse Brasil 2016. Com elenco de profissionais e não-profissionais o espetáculo é uma celebração coletiva da dança capaz de questionar o que significa dançar bem, mostrando como cada performer, cada corpo, entende e traduz a sua propria dança. $\mathrm{O}$ artigo propõe também uma breve análise comparativa entre Gala e Amadores, da Cia Hiato.

Palavras-chave: Dança, Teatro, Não-profissionais, Cidadão, Espectador, Compartilhamento da arte.

\section{Abstract}

This article is a reflection on the dance piece Gala, by French choreographer Jérôme Bel, which was performed in São Paulo as part of the FranceDanse Brasil 2016 festival. With a cast of professionals and non-professionals, the work is a collective celebration of dance that questions what it means to dance well by showing how each performer, each body, understands and translates its own dance. The article also proposes a brief comparative analysis between Gala and Amadores, by Cia Hiato's.

Keywords: Dance, Theater, Non-professionals, Citizens, Spectator, Art Sharing.

Gala coloca em primeiro plano as expectativas do público e borra os limites entre o fracasso e o sucesso, sugerindo que o teatro é uma comunidade tanto em cena quanto fora dela. É uma façanha ferozmente divertida e profundamente radical. Roslyn Sulcas, New York Times ${ }^{1}$

Encarar de outro modo a dança. Abrir o teatro àqueles que nunca nele são representados. Perguntar-se: como compartilhar a arte? Marie-José Malis, diretora teatral ${ }^{2}$

1 Declaração apresentada no programa do espetáculo.

2 Declaração apresentada no programa do espetáculo. 
Falemos de diferença, diversidade.

De quê? De raça, idade, sexo, gênero, corpos, expectativas, sonhos, desejos, realizações, frustrações, passado, presente, futuro. Já falamos tanto de tudo isso, não é verdade? Falamos. Gala, do coreógrafo francês Jérôme $\mathrm{Bel}$, aborda esses temas. E sem falar.

O espetáculo abre nossos olhos e corações para receber as mais diferentes pessoas dançando. Dançando e nos mostrando as diferentes maneiras que sentem a dança.

Quinze pessoas de diferentes gerações e formação fazem esse espetáculo. Alguns são profissionais, mas a maioria é gente como você e eu. Gente que gosta de dançar, que sente e expressa a dança do seu jeito a partir do seu repertório pessoal e cultural. Gente com diferentes habilidades, com diferentes corpos, e que nos mostram seus "eus dançantes." Com isso, conseguem nos envolver no jogo, na brincadeira de dançar, errar, arriscar, de se expor descarada e lindamente. E, como público, nós nos divertimos, nos identificamos com suas danças e temos muita vontade de estar no palco.

Os tempos atuais tem nos apresentado muitos grupos e artistas que desenvolvem seus espetáculos a partir da ideia do teatro documental e se valem de depoimentos reais de pessoas de diferentes segmentos sociais para dar voz a elas. Tempos quando ainda outros grupos e artistas exploram as ideias e possibilidades do "real" no teatro usando dispositivos e uma dramaturgia capazes de nos mostrar quem são - de verdade! - aqueles performers, o que desejam, o que alcançam, ou mesmo seus fracassos e frustrações. Muitos são espetáculos interessantes, com pesquisa de linguagem provocadora e posicionamento político comprometido com um diagnóstico social a ser revelado e com as mudanças sociais desejadas. Espetáculos que buscam, ainda, o envolvimento crítico do público que, com seu olhar, e muitas vezes participação direta, pode completar o espetáculo apresentado e repensar as suas posições, preconceitos e atitudes. A realidade assim trabalhada busca questionar os limites entre ator/pessoa/performer, entre realidade e ficção, revê e/ou amplia a relação ator-espectador, busca dar visibilidade a cidadãos silenciados por uma cidade desigual e injusta, e tornados invisíveis por um sistema político-ecônomico que os exclui. 
Tudo bem. Mas, mesmo trabalhando com muitas dessas ideias, Gala faz outra coisa. O espetáculo entrega o palco e a plateia a cidadãos comuns. Profissionais ou amadores - amadores porque amam o que estão fazendo -, são eles os protagonistas de Gala. E todos se apresentam diante de nós em igualdade de condições.

\section{O elenco}

Quem é o elenco de Gala?

O espetáculo foi primeiro criado e ensaiado na França e é recriado por Jérôme Bel e dois assistentes em cada cidade onde se apresenta, com elenco local, durante alguns meses e com apenas alguns dias de ensaios. A composição do elenco local é parte fundamental no processo de criação do espetáculo.

O grupo que participa do espetáculo é escolhido de acordo com um protocolo encaminhado pelo coreógrafo Jérôme Bel. Ele pede que um terço do elenco seja de profissionais e dois terços de não-profissionais, e que atendam, na medida do possível, as seguintes especificações: 2 bailarinos clássicos, 2 bailarinos de dança contemporânea, 2 atores, 1 atriz, 2 crianças entre 6 e 10 anos, 2 adolescentes entre 12 e 17 anos, 3 pessoas aposentadas, 1 cadeirante, 1 pessoa com síndrome de Down, 1 gay/travesti/transgênero/ drag, 1 pessoa que faça twirling e 3 outros não-profissionais.

Em países onde o espetáculo foi encenado, o elenco contou com 20 pessoas. Em São Paulo, contou com um grupo de 15: 2 bailarinos clássicos, 2 de dança contemporânea, 2 atores, 1 criança, 1 aposentado, 1 cadeirante, 1 pessoa com síndrome de Down, 1 transsexual, 1 praticante de twirling e 3 outros não-profissionais.

Os interessados em fazer parte do elenco receberam uma carta de Jérôme Bel:

\section{Carta aos participantes de Gala}

Olá,

Meu nome é Jérôme Bel. Sou um coreógrafo francês que vive em Paris. http://www.jeromebel.fr/ 
Estou muito feliz que você se interessou em participar da peça chamada Gala.

A ideia principal do espetáculo é a de poder juntar no palco um grupo de vinte pessoas bastante diferentes umas das outras: bailarinos, é claro, alguns atores, mas em geral amadores, como crianças, adolescentes e idosos. No espetáculo, cada um irá dançar de acordo com sua habilidade. Não haverá aulas nem avaliações. Eu não vou Ihes mostrar nada. Vou apenas pedir aos participantes para realizarem certos movimentos de dança sozinhos ou em grupos. Não é necessário realizar os movimentos corretamente. Algumas diretrizes serão dadas para encenar a coreografia.

$[\ldots]$

Para a peça, irei precisar que você me envie uma foto de rosto e uma de corpo inteiro com o figurino: roupas de dança, como collant, legging etc.; roupas que ficam justas ao corpo, o mais justo possível. Também, quanto mais colorido, brilhante, cintilante possível, melhor.

Mas, acima de tudo, não compre nada; vire-se com o que você tem ou pegue emprestado, e use o que conseguir combinar. Não tem problema se não for perfeito! Você pode achar alguns exemplos de figurino no site da companhia: <http://www.jeromebel.fr/performances/pictures?performance $=$ Gala $>$.

Além disso, eu preciso que você prepare um solo de dança que você goste de dançar; talvez alguma coisa que tenha aprendido em uma aula de dança. Pode ser contemporâneo, clássico, tradicional (africano, chinês, siciliano, húngaro, regional, iídiche...), popular (bollywood, samba, zouk, punk...), sapateado, uma improvisação, yoga ou alguma rotina eurrítmica, uma performance atlética (aeróbica, tai chi chuan ou artes marciais etc.), ballet, malabares etc... Deve durar ao redor de 2 minutos. Você é muito bem-vindo para usar música, mas silêncio também é uma possibilidade.

$[\ldots]$

É imperativo que você possa participar tanto dos ensaios quanto das performances.

$[\ldots]$

Você também deve saber que eu talvez tenha que escolher entre vocês. É um equilíbrio geral do grupo que irá motivar minha decisão, e não quaisquer habilidades individuais; o objetivo central do espetáculo é o de construir uma comunidade o mais diversa possível.

Novamente, agradeço pelo seu interesse no projeto. Espero vê-lo em breve.

Jérôme Bel

E o grupo é formado. 


\section{Gala}

O espetáculo começa com uma das pessoas - que a partir de agora chamarei de performer - entrando e colocando no canto esquerdo do palco (perspectiva do público) um cavalete com muitas folhas de papel. A performer, então, vira a primeira folha e lemos: "Ballet".

Uma música de Chopin começa e, a partir desse momento, cada um dos quinze performers cruza o palco fazendo uma pirueta. Depois, cada um cruza novamente o palco fazendo um grand-jeté.

Como um cadeirante faz um grand-jeté ou uma pirueta? E uma pessoa idosa? Uma criança? Alguém com sobrepeso? Uma pessoa com síndrome de Down? Só vendo. Mas todos fazem o seu grand-jeté e a sua pirueta e todos são igualmente encantadores. A execução perfeita do que seria o "passo original" rapidamente deixa de ter importância ou interesse, pois as variações pessoais para cada um daqueles passos são muito mais divertidas e emocionantes. $E$ imediatamente ganham a plateia.

O espetáculo segue. As páginas seguintes trazem, cada uma, o tema da cena que será apresentada: "Valsa", "Improvisando em silêncio - 3 minutos Todos", “Michael Jackson”, “Agradecimento," "Solo" e, por fim, "Com Minha Companhia".

Ao som de uma "Valsa" de Strauss, os performers entram em duplas, uma de cada vez, valsando. São duplas improváveis, duplas previsíveis, duplas que conseguem valsar juntas, outras que nem tanto. A cada dia de ensaio ou apresentação, uma nova lista de duplas era afixada na coxia. Os performers nunca sabiam antecipadamente com quem dançariam.

"Improvisando em silêncio - 3 minutos - Todos" traz os performers se movimentando individualmente como querem. Pode ser visto como um aquecimento, pode ser um movimento que sintam necessidade de fazer. São 3 minutos em silêncio para improvisarem e aproveitarem à vontade.

A próxima palavra-tema que lemos é "Michael Jackson". E como vocês podem imaginar, cada um entra e faz o seu moonwalk ao som da genial "Billie Jean". O público delicia-se, por exemplo, ao ver uma das performers, uma bailarina de tutu e tudo, fazendo o moonwalk do seu jeito. $O$ contraste entre mundos tão radicalmente diferentes como o do ballet clássico e o de Michael 
Jackson de repente explode na nossa frente e passa a conviver com harmonia e humor.

Depois de "Michael Jackson", a página que se revela nos diz que veremos "Agradecimento". E, em silêncio, um por um, os performers entram pela coxia esquerda, andam até o centro do palco, param, fazem o seu agradecimento e recebem seus aplausos. Exatamente como acontece no final de um espetáculo - embora aqui não seja o caso, pois Gala continua.

Quando a música de uma cena acaba, o silêncio permanece até que a página seguinte seja virada e o próximo tema se revele. É um final claro para cada um dos momentos dançados e é também parte integrante de uma estrutura de espetáculo que não busca desenhar nenhum arco dramático ou contar uma história com começo, meio e fim (estejam eles na sequência que for...). São momentos dançantes e dançados da vida de cada um dos performers e também do grupo que acabaram formando ao participarem de Gala.

Depois do "Agradecimento", é a performer-senhora-não-profissional quem entra e nos revela a próxima palavra-tema: "Solo".

E o "Solo" é dela, coreografado por ela para o axé "Extravasa", hit de Cláudia Leitte ${ }^{3}$. A letra da música de alguma maneira traz um pouco da graça do espetáculo quando diz:

\author{
Extravasa \\ Libera e joga tudo pro ar \\ Eu quero ser feliz antes de mais nada \\ Extravasa \\ Libera e joga tudo pro ar, ar, ar, ar, ar, ar, ar
}

A plateia adora, se diverte, ri e acompanha com palmas a coreografia. No final, quando a música termina, a mesma performer vai novamente até o cavalete, e em silêncio muda a página. Lemos: "Com Minha Companhia". Ainda em silêncio, ela vai até o fundo do palco e a vemos chamando seus parceiros de cena. À medida em que começam a entrar, o público logo entende o que vai acontecer e já começa a rir. Com todos no palco, ela se coloca à frente

3 Todas as músicas foram escolhidas pelos performers com exceção de quatro, que foram escolhidas pela companhia: a primeira de Chopim, a valsa de Strauss, "Billie Jean" de Michael Jackson e "New York, New York", de Fred Ebb e John Kander, imortalizada nas vozes de Frank Sinatra e Liza Minelli. 
do grupo e mais uma vez começa a coreografia para a música "Extravasa", só que agora o seu "solo" é dançado por todos.

A partir desse momento, cada performer faz a sua coreografia na companhia de todo o grupo. O grupo é a "Minha Companhia" que interpreta a criação de cada um.

O performer-cadeirante coreografou "Blowing in the Wind", de Bob Dylan.

O senhor aposentado dançou o hino gay "Macho Man", do grupo Village People, para total diversão da plateia.

O performer-transsexual criou uma coreografia sem música que começa com todos no fundo do palco, de costas para o público, tentando fazer movimentos, sem conseguir completá-los. Começam os movimentos e caem. Começam e caem. Uma coreografia de quedas.

Já a performer-ginasta parece levar mais a sério a sua criação de ginástica rítmica com bastões. Ela distribui bastões para o grupo que, por sua vez, tenta realizar aqueles movimentos difíceis que fazem o bastão voar e girar no ar acompanhados de movimentos igualmente difíceis no chão. O grupo tenta... os bastões caem, os pivôs e espacates são quase impossíveis de realizar, mas todos se envolvem e tentam fazer a coreografia.

A criança de 11 anos faz... movimentos de criança. Movimentos soltos, galopes, saltos, passeios livres pelo espaço.

Uma das coreografias que mais ganhou a adesão do público foi a do performer que dançou a música "Festa no mar", cantada por Márcia Freire. Uma brincadeira com os movimentos do axé que trazem fortes movimentos de quadril, flexão de braços e pernas, sempre com uma sensualidade exacerbada que, aqui, acontecem com humor e alegria.

As músicas escolhidas para as coreografias acabam expondo identidades, afirmando diferenças, criando cumplicidades e mostrando como cada pessoa, cada corpo, tem o seu próprio jeito de viver e traduzir a sua história. Um espetáculo festivo que não apenas questiona as convenções do que seja uma apresentação de dança, como faz dela uma representação mais democrática que, ao menos ali, torna-se aberta e accessível a todos. Uma grande utopia de mundo conquistada em um nem tão pequeno espaço de palco. 
A coreografia final é feita ao som de "New York, New York". A ideia principal da música é a de que, caso a gente consiga vencer em uma cidade difícil como New York, pode-se vencer em qualquer lugar. Uma ideia que imediatamente dialoga com tudo o que aquele grupo fez em cena, com o que expuseram e compartilharam com o público. Afinal, São Paulo é uma cidade igualmente desafiadora, difícil, exigente, excludente, violenta e, se conseguirmos vencer aqui, poderemos vencer em qualquer outro lugar. Fato que o grupo deixa claro quando, no momento da música em que dançam "If I can make it there, l'll make it everywhere. It's up to you, New York, New York,', eles se reúnem em círculo, combinam em segredo alguma coisa, e, no momento em que se cita o nome da cidade, a música sai e todos gritam "São Paulo, São Paulo". Enquanto seguem cantando "It's up to you, São Paulo, São Paulo" se desnudam e espalham peças de roupa pelo palco.

Fim. Um final apoteótico e feliz.

Durante as coreografias de "Com Minha Companhia", vemos os performers usando peças de figurino uns dos outros. E da mesma maneira que os movimentos acontecem diferente no corpo de cada um, também os figurinos vestem diferente cada um, o que acaba provocando outras e novas associações para o espectador. Em todo o espetáculo, o que vale para um, vale para o outro. Todos se apresentando em igualdade de condições e sem julgamentos.

Há anos, conversando com um amigo diretor de teatro, eu disse que gostava do erro. Ele ficou quase indignado com a minha afirmação e se disse voltado ao acerto, ao certo, ao sucesso. Eu disse, não, o erro é aquilo que escapa, que escapa do previamente combinado ou imposto, que se abre para as surpresas de um momento, que transborda para além do previsto ou ensaiado, é o que faz o tempo às vezes parar, outras vezes correr. É vida.

Gala é vida. A mais bonita, generosa e alegre que vi no palco nos últimos tempos. Muitas vezes essa vida não é fácil, é verdade, mas nesse espetáculo estão todos dispostos e disponíveis para dançá-la e expô-la. O senhor aposentado que nunca havia pisado em um palco antes disse à produtora Julia Gomes: "Não sabia que tinha outra vida." O cidadão comum pode, assim, tornar-se protagonista do espetáculo da sua vida. 


\section{Gala e Amadores conversando}

Termino falando, ainda que brevemente, de Amadores da Cia Hiato ${ }^{4}$, pelos múltplos pontos de contato com Gala e, claro, pelo que a companhia alcançou com esse espetáculo.

Quem era o elenco de Amadores?

Em 2015, um anúncio nos jornais procurava "artistas amadores e pessoas sem experiência no palco para espetáculo teatral.' Das mais de duzentas pessoas que responderam ao anúncio, treze delas trabalharam ao lado de cinco atores da companhia formando, juntos, o elenco de Amadores.

O espetáculo era feito de depoimentos de superação dos participantes e, também aqui, o que encanta não é a atuação perfeita ou especialmente talentosa de cada um, mas a possibilidade de vermos diferentes pessoas falando sem medo sobre questões importantes e delicadas de suas vidas e as formas que encontraram para superá-las. Em seu site o grupo diz:

O espetáculo é um relato poético, mas também um manifesto artístico. Uma galeria de retratos vivos. Um passeio por histórias e contextos que poderiam nos separar, mas que se aproximam em cena. Um evento que almeja o estabelecimento (ainda que só poético, porque tão distante da experiência real) de um palco sem divisões ${ }^{5}$.

Também eles praticando a utopia de uma sociedade mais igualitária no espaço de um palco. Trago para Amadores o que Jérôme Bel falou sobre a sua dança ser "um instrumento para as pessoas expressarem coisas que em outros lugares elas não podem"6.

A maior diferença entre os dois espetáculos é a de que Amadores tem uma narrativa que conduz o espetáculo e amarra os depoimentos. Ela se vale da história (também de superação) do filme Rocky, um lutador, com Sylvester Stallone, assim como de sua grandiosa música-tema "Gonna fly now". O uso da história e da música do filme no espetáculo de um lado evoca a imagem

4 Amadores estreou em abril de 2016, no SESC Consolação, São Paulo.

5 Disponível em: <http://ciahiato.com.br>.

6 "A tool for people to express things they can't elsewhere." BEL, J. apud BURKE, S. An experimental choreographer who isn't afraid of failure. The New York Times, New York, 18 out. 2016. 
de um ringue no qual não apenas Rocky como todos do elenco de alguma maneira tiveram que lutar e, de outro, critica com humor o glamour tão comumente construído e presente nos filmes hollywoodianos para falar de histórias que são, acima de tudo, tensas, difíceis, estressantes, custosas para todos os envolvidos e muito, muito raramente, glamourosas.

É interessante ver que, tanto em Amadores como em Gala, o palco assume uma função dupla e aparentemente contraditória: ele expõe e ele protege. Expõe por revelar publicamente as dificuldades e individualidades dos performers a um grande e desconhecido público; protege ao reunir e apresentar a esse mesmo público um grupo diversificado que, unido e solidário uns com os outros, concede essa exposição.

Agradeço a Jérôme Bel e sua equipe por me permitirem ver o video do espetáculo. Agradeço à produtora do espetáculo em São Paulo Julia Gomes por viabilizar meu contato com eles e por me oferecer valiosas informações sobre a realização do espetáculo. Mesmo tendo visto Gala em São Paulo, sem o video não poderia ter escrito esse artigo. Agradeço, ainda, a Fábio Alexandre Gomes que gentilmente cedeu suas fotos de Gala para este artigo.

Gala integrou a primeira edição latina da FranceDanse, mostra de dança contemporânea francesa. O evento aconteceu de 18 de agosto a 15 de novembro de 2016, reuniu 15 espetáculos e foi apresentado nas cidades de Porto Alegre, São Paulo, Rio de Janeiro, Fortaleza, Recife, Brasília, Belo Horizonte, Curitiba e Londrina. Em São Paulo, as apresentações de Gala aconteceram no SESC Bom Retiro, dias 29 e 30 de outubro de 2016.

Jérôme Bel vive em Paris e trabalha em diversos países. Realizou os seguintes espetáculos: Nom donné par l'auteur (1994) é uma coreografia de objetos. Jérôme Bel (1995) tem por base a total nudez dos intérpretes. Shirtologie (1997) põe em cena um bailarino usando dezenas de camisetas. Le dernier spectacle (1998) cita um solo da coreógrafa Susanne Linke, e também Hamlet e André Agassi. Xavier Le Roy (2000) leva a assinatura de Jérôme Bel, mas foi totalmente realizada pelo coreógrafo Xavier Le Roy. The show must go on (2001) reúne vinte intérpretes, dezenove canções pop e um DJ. Véronique Doisneau (2004) é um solo sobre o trabalho da bailarina da Opéra de Paris Véronique Doisneau. Isabel Torres (2005), espetáculo montado para o balé do Teatro Municipal do Rio de Janeiro, é a versão brasileira de Véronique 
Doisneau. Pichet Klunchun and myself (2005) foi concebida em Bangcoc com o bailarino tradicional tailandês Pichet Klunchun. Segue-se Cédric Andrieux (2009), bailarino de Merce Cunningham. 3Abschied (2010) é uma colaboração de Anne Teresa De Keersmaeker e Jérôme Bel a partir de $O$ canto da Terra, de Gustav Mahler. Disabled theater (2012) é uma peça com os atores profissionais com deficiência de aprendizagem do Theater Hora, companhia com base em Zurique. Cour d'honneur (2013) põe em cena catorze espectadores do Pátio de Honra do Palácio dos Papas, em Avignon. Com Gala (2015), o coreógrafo põe para dançarem profissionais da dança e amadores de procedências diversas. Para Tombe (2016), peça criada a convite da Ópera Nacional de Paris, Jérôme Bel propôs aos bailarinos que convidassem para um duo a pessoa com quem nunca compartilhariam uma cena.

Recebido em 21/03/2017 Aprovado em 27/04/2017 Publicado em 17/07/2017 

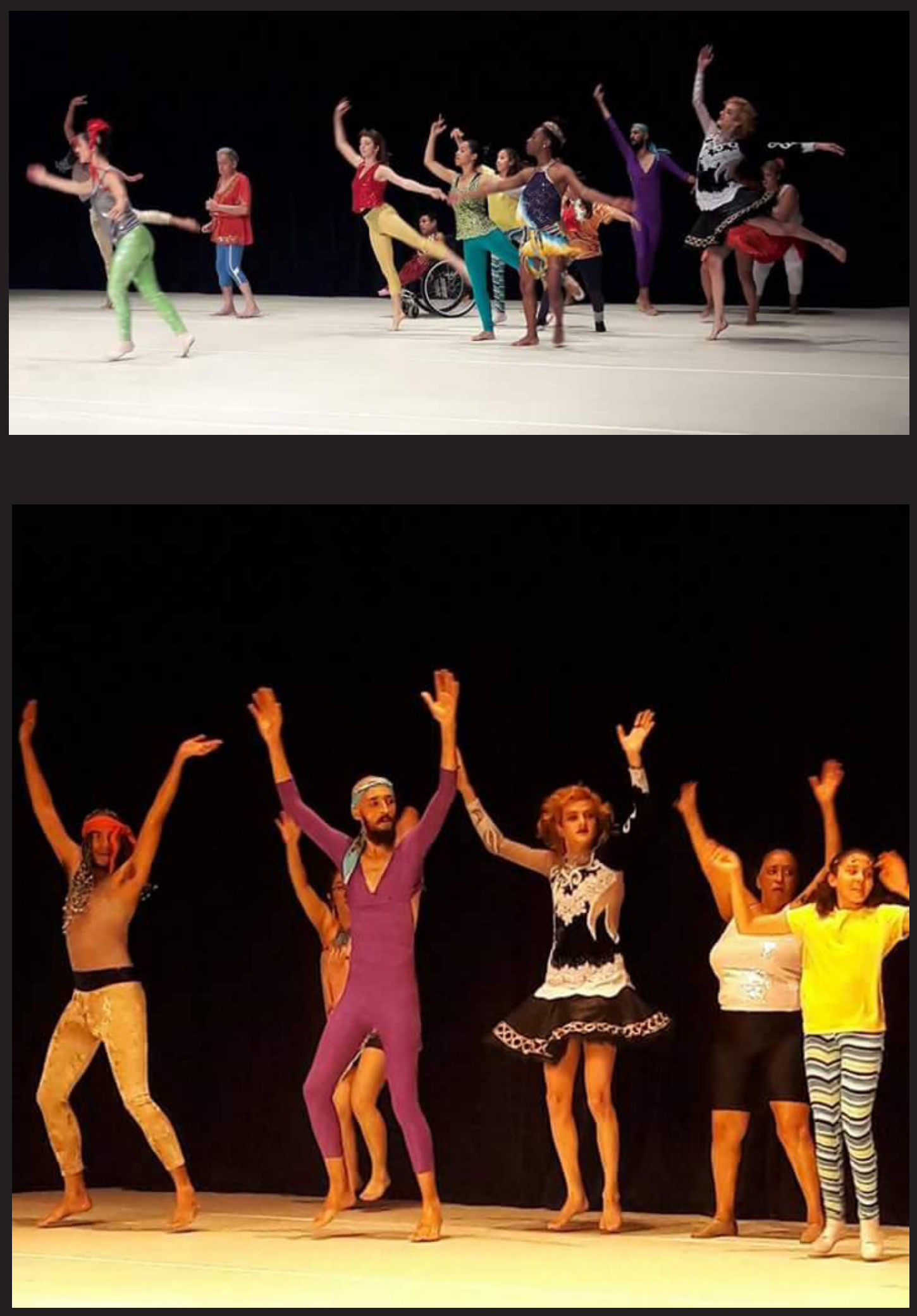


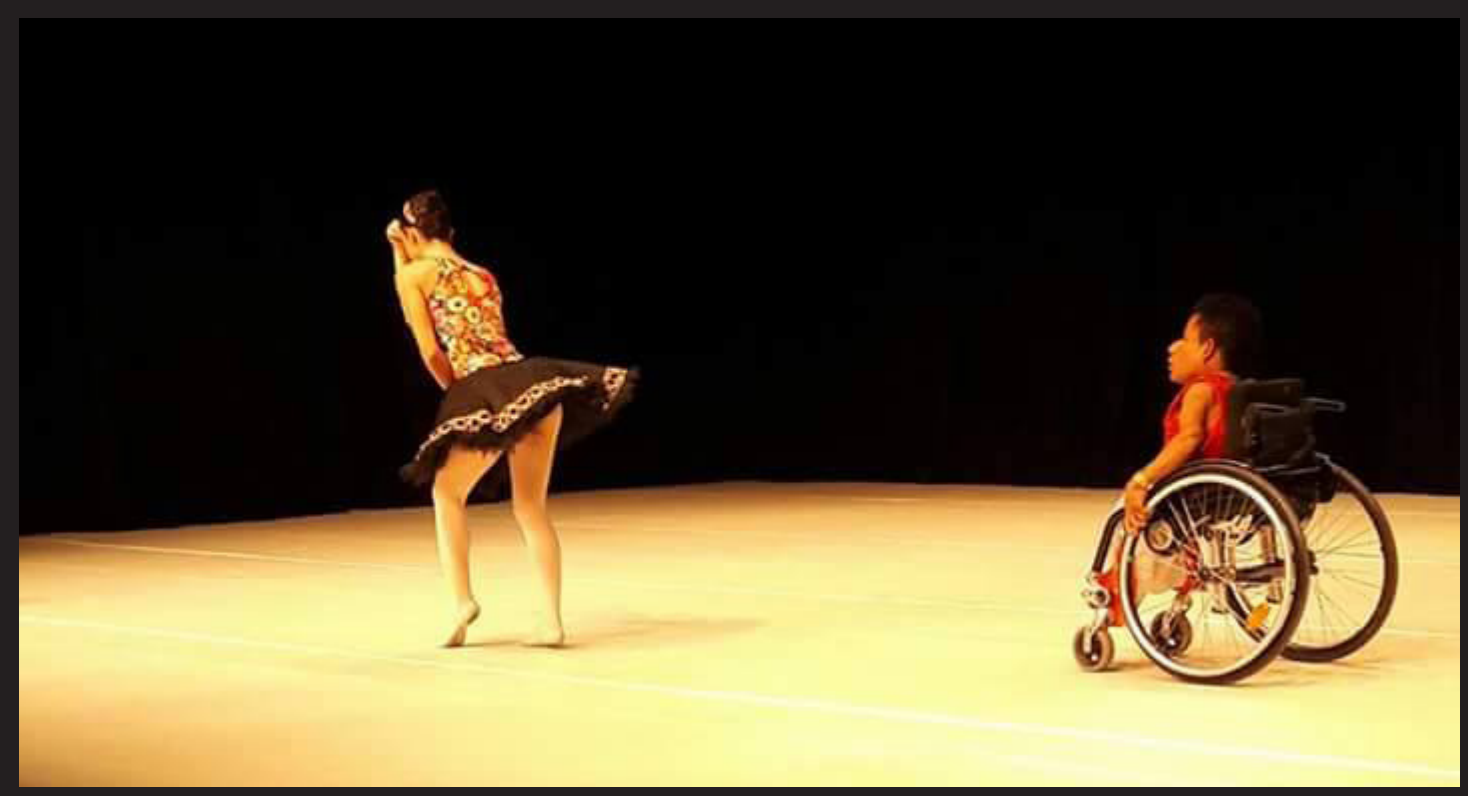

